However, undoubtedly the use of echocardiography (including transoesophageal echocardiography), laboratory findings and venous ultrasonography should be encouraged in patients with suspected high-risk PE. Management decisions should be taken based on all collected data on a case by case basis. Each test comes to the rescue of the others. 'One for all and all for one'.

\section{Competing interests None.}

Provenance and peer review Commissioned; not externally peer reviewed.

Published Online First 12 November 2010

Thorax 2011;66:2-4. doi:10.1136/thx.2010.151316

\section{REFERENCES}

1. Torbicki A, Perrier A, Konstantinides S, et al; Task Force for the Diagnosis and Management of Acute Pulmonary Embolism of the European Society of Cardiology. Guidelines on the diagnosis and management of acute pulmonary embolism. Eur Heart J 2008;29:2276-315

2. Kearon C, Kahn SR, Agnelli G, et al; American College of Chest Physicians. Antithrombotic therapy for venous thromboembolic disease: American College of Chest Physicians Evidence-Based Clinical Practice Guidelines (8th Edition). Chest 2008;133(6 Suppl):454S-545S.
3. Goldhaber SZ. Assessing the prognosis of acute pulmonary embolism: tricks of the trade. Chest 2008;133:334-6.

4. Watts JA, Marchick MR, Kline JA. Right ventricular heart failure from pulmonary embolism: key distinctions from chronic pulmonary hypertension. J Card Fail 2010;16:250-9.

5. Toosi MS, Merlino JD, Leeper KV. Prognostic value of the shock index along with transthoracic echocardiography in risk stratification of patients with acute pulmonary embolism. Am J Cardiol 2008;101:700-5.

6. Sanchez 0, Trinquart L, Colombet I, et al. Prognostic value of right ventricular dysfunction in patients with haemodynamically stable pulmonary embolism: a systematic review. Eur Heart J 2008;29:1569-77.

7. Holley AB, Cheatham JG, Jackson JL, et al. Novel quantitative echocardiographic parameters in acute PE. J Thromb Thrombolysis 2009;28:506-12.

8. Vitarelli A, Terzano C. Do we have two hearts? New insights in right ventricular function supported by myocardial imaging echocardiography. Heart Fail Rev 2010;15:39-61.

9. Becattini C, Vedovati MC, Agnelli G. Prognostic value of troponins in acute pulmonary embolism: a meta-analysis. Circulation 2007;116:427-33.

10. Lega J-C, Lacasse $Y$, Lakhal L, et al. Natriuretic peptides and troponins in pulmonary embolism: a meta-analysis. Thorax 2009;64:869-75.

11. Jiménez D, Aujesky D, Díaz G, et al; the RIETE Investigators. Prognostic significance of concomitant deep vein thrombosis in patients presenting with acute symptomatic pulmonary embolism. Am J Respir Crit Care Med 2010;181:983-91.
12. Yamaki T, Nozaki M, Sakurai H, et al. Presence of lower limb deep vein thrombosis and prognosis in patients with symptomatic pulmonary embolism: preliminary report. Eur J Vasc Endovasc Surg 2009;37:225-31.

13. Girard P, Sanchez 0, Leroyer C, et al. Deep venous thrombosis in patients with acute pulmonary embolism: prevalence, risk factors, and clinical significance. Chest 2005;128:1593-600.

14. Jiménez D, Aujesky D, Moores L, et al. Combinations of prognostic tools for identification of high-risk normotensive patients with acute symptomatic pulmonary embolism. Thorax 2011;66: 75-81.

15. Kostrubiec M, Pruszczyk P, Bochowicz A, et al. Biomarker-based risk assessment model in acute pulmonary embolism. Eur Heart J 2005;26:2166-72.

16. Binder L, Pieske B, Olschewski $\mathrm{M}$, et al. N-terminal pro-brain natriuretic peptide or troponin testing followed by echocardiography for risk stratification of acute pulmonary embolism. Circulation 2005;112:1573-9.

17. Scridon T, Scridon C, Skali H, et al. Prognostic significance of troponin elevation and right ventricular enlargement in acute pulmonary embolism. $\mathrm{Am} \mathrm{J}$ Cardiol 2005:96:303-5.

18. Stein PD, Matta F, Janjua M, et al. Outcome in stable patients with acute pulmonary embolism who had right ventricular enlargement and/or elevated levels of troponin I. Am J Cardiol 2010;106:558-63.

19. Vorobiof G, Kadiev S. Evaluation of right ventricular size on computed tomography: unreliable at best. Am J Med 2008;121:e15; author reply e17.

\title{
How does diesel exhaust impact asthma?
}

\section{John R Balmes}

Both air pollution health effects researchers and air quality regulatory agencies have been paying increased attention to emissions from motor vehicles in recent years. A growing body of scientific literature supports the concept that exposure to roadways with high traffic density is associated with adverse health effects, including increased risk of negative asthma outcomes. Heavy-duty diesel-powered vehicles like trucks and buses are often driven more frequently on roadways with high traffic density and, as such, diesel exhaust has been suspected to be a major cause of traffic-associated asthma morbidity.

University of California, San Francisco and Berkeley, USA Correspondence to John R Balmes, University of California, San Francisco and Berkeley, USA; jbalmes@medsfgh.ucsf.edu
Diesel exhaust is somewhat akin to tobacco smoke in that it is a mixture of particles and gases with many chemical constituents. Diesel exhaust particulate (DEP) is mostly elemental carbon with about 20-40\% adsorbed organic compounds, but sulfates, nitrates and metals are also present. ${ }^{1}$ Polycyclic aromatic hydrocarbons (PAHs) and related compounds such as quinones have been touted as the most toxicologically relevant constituents of DEP, primarily because of their redox potential and ability to cause oxidative stress. ${ }^{2}$ More than $90 \%$ of DEP mass is in particles $>1 \mu \mathrm{m}$ in diameter that can easily be inhaled into the deep lung. ${ }^{1}$ The vapour phase of diesel exhaust includes carbon monoxide, oxides of nitrogen, sulfur oxides and volatile organic compounds, many of which are known to be respiratory tract irritants such as formaldehyde, acrolein and naphthalene (a volatile PAH).
Many in vitro and animal experimental studies support the toxicity of DEP. ${ }^{1-4}$ The concept of a tiered response to DEP that is dose-dependent has been advanced which posits that low doses induce oxidative stress and upregulation of antioxidant and phase II enzymes, intermediate doses lead to activation of inflammatory signalling cascades and higher doses to cytotoxicity and apoptosis. $^{2}$ Organic extracts of DEP have been studied with regard to their ability to induce oxidative stress and the polar fraction containing quinones showed the greatest effect. ${ }^{2}$ Mechanisms by which DEP could potentially exacerbate asthma include enhancement of airway inflammation, non-specific airway hyperresponsiveness and specific allergic responses. Several groups have shown that DEP can act as an adjuvant when combined with an experimental allergen resulting in enhanced IgE antibody production and increased allergic inflammation and airway hyper-responsiveness in mice. ${ }^{56}$ One such study showed that treatment with the antioxidant $\mathrm{N}$-acetyl cysteine blunted the adjuvant effects of DEP, providing further supportive evidence for the role of oxidative stress in DEP toxicity. ${ }^{6}$

A number of studies have found increased risks of asthma outcomes in 
children and adults who live near roadways with high traffic counts. The authors of two separate comprehensive reviews judged the evidence for traffic as a risk factor for both asthma exacerbation and onset to be strong. ${ }^{7} 8$ Several recently published reports have further highlighted the apparent causal link between exposure to traffic and asthma onset. In a study of over 2700 never-smoking adults enrolled in the Swiss SAPALDIA cohort study, Kunzli et al showed that new-onset asthma was associated with exposure to traffic-related particulate matter (PM). ${ }^{9}$ With a similar prospective design, McConnell et al found that development of asthma was associated with traffic-related pollution at home and at school in nearly 2500 young children participating in the southern California Children's Health Study. ${ }^{10}$ The results of a smaller study in 149 children aged 4-12 years with careful measurement of the composition and source apportionment of PM showed that asthma symptoms were associated with exposure to traffic-related PM. ${ }^{11}$

Despite the increasing body of epidemiological evidence to support a causal link between traffic-related air pollution and asthma outcomes, it has been difficult to tease out the contribution of diesel emissions in large cohort studies due to the lack of either a good exposure metric or biomarker. Although diesel emissions are a major component of atmospheric elemental carbon, they are not the only source, especially as diesel engine technology improves and emissions of DEP decrease. Perhaps the most convincing evidence to date that diesel exhaust can induce exacerbations of asthma comes from a field study in London where subjects with asthma walked in Hyde Park and along a busy street with a lot of heavy-duty vehicle traffic. ${ }^{12}$ Exposures to fine PM, ultrafine PM, elemental carbon and nitrogen dioxide were all considerably greater on the busy street than in the park. Significant reductions in forced expiratory volume in $1 \mathrm{~s}$ and increases in sputum myeloperoxidase were observed after the walk on the street compared with after the walk in the park.

Because it has been so difficult to isolate the effects of diesel exhaust from those of other traffic-related emissions in epidemiological studies, controlled human exposure studies have played a major role in our understanding of the potential effects of diesel exhaust in asthma. Evidence of airway inflammation has been observed in healthy volunteers in multiple studies, ${ }^{13-15}$ and increased airway hyperresponsiveness has been seen in asthmatic subjects. ${ }^{16}$ Curiously, however, a previous controlled human exposure study of diesel exhaust in subjects with asthma found no increase in airway inflammation. ${ }^{17}$ The report in this issue of Thorax (see page 12) presents further convincing evidence from the same laboratory that exposure to a high concentration of diesel exhaust from a well-characterised engine has less inflammatory effect in subjects with asthma than in healthy individuals. ${ }^{18}$ This study has the usual limitations of controlled human exposure studies. The sample size was small compared with an epidemiological study, only subjects with relatively mild asthma were studied and the exposure was not necessarily representative of real-world conditions, such that the results may not be generalisable. In addition, the engine used in the study is no longer representative of current diesel technology. ${ }^{3}$

Given the consistency of the finding from the Sandstrom group that subjects with asthma have less diesel exhaustinduced inflammation than non-asthmatic subjects, the important question is why? This is of particular interest since individuals with asthma are typically considered by environmental regulatory agencies as having heightened susceptibility to inhaled oxidant pollutants precisely because they have underlying airway inflammation and hyper-responsiveness. The data on the lung function responses of subjects with asthma to diesel exhaust, both from the current report and a previous study, ${ }^{16}$ do indicate that they have increased airway responsiveness and greater bronchoconstriction than normal subjects, as one would expect. But what is the mechanism responsible for the downregulation of the inflammatory response to diesel exhaust in asthma?

Asthma is known to be associated with increased oxidative stress in the airways. ${ }^{19}$ It is possible that antioxidant defences in individuals with asthma are sufficiently upregulated in the face of a chronic burden of increased reactive oxygen species such that insufficient airway injury from diesel exhaust occurs to trigger activation of inflammatory signalling cascades. Alternatively, the persistent airway inflammation of asthma may be associated with upregulation of anti-inflammatory pathways such that mild injury from inhaled diesel exhaust is an inadequate stimulus for the induction of an inflammatory response. Further research will be needed to clarify the mechanistic basis for the differential response of subjects with and without asthma to diesel exhaust.
If diesel exhaust is not inducing much of a direct airway inflammatory response in individuals with asthma, then how does one explain the strong links with trafficrelated pollution and asthma outcomes observed in epidemiological studies? One possibility is that the primary impact of diesel emissions is as an adjuvant to the effects of aeroallergens. As noted above, considerable evidence that exposure to DEP can enhance allergic responses has been reported from animal studies. Although no such studies have been conducted in humans with allergic asthma, controlled human exposure studies of subjects with allergic rhinitis have been reported. Diaz-Sanchez and colleagues, using nasal challenge to DEP, have documented enhanced allergic inflammatory responses to ragweed as well as enhanced sensitisation to a neoantigen. ${ }^{20} 21$ Moreover, they reported that variants in two antioxidant enzymes, glutathione S-transferase $\mu$ and pi, are associated with increased risk of DEP enhancement of allergic nasal inflammatory responses. ${ }^{22}$

Whether the primary mechanism by which diesel emissions affect asthma is through an effect on immune regulation or not, greater understanding of the contribution of this pollutant mixture to trafficrelated asthma morbidity is needed. Control strategies can be better designed if mechanistic knowledge is available. If the major effect of diesel exhaust on individuals with asthma is merely to induce mild bronchoconstriction, then the current approach of promoting cleaner diesel engines with reduced DEP emissions may be sufficient. However, new technology engines may produce more nitrogen oxides and ultrafine particles. These pollutants may have effects other than mild bronchoconstriction. Continued support of research on the health effects of diesel exhaust, especially from newer engines, is warranted.

Competing interests None.

Provenance and peer review Commissioned; not externally peer reviewed.

Thorax 2011;66:4-6. doi:10.1136/thx.2010.145391

\section{REFERENCES}

1. US Environmental Protection Agency (EPA). Health effects assessment document for diesel engine exhaust. EPA/600/8-90/057F. National Center for Environmental Assessment, Office of Research and Development. Washington, DC: US EPA, 2002.

2. Gilmour MI, Jaakkola MS, London SJ, et al. How exposure to environmental tobacco smoke, outdoor air pollutants, and increased pollen burdens influences the incidence of asthma. Environ Health Perspect 2006;114:627-33.

3. Hesterberg TW, Long CM, Bunn WB, et al. Non-cancer health effects of diesel exhaust: 
a critical assessment of recent human and animal toxicological literature. Crit Rev Toxicol 2009;39:195-227.

4. Li N, Wang M, Oberley TD, et al. Comparison of the pro-oxidative and proinflammatory effects of organic diesel exhaust particle chemicals in bronchial epithelial cells and macrophages. J Immunol 2002;169:4531-41.

5. Miyabara $\mathbf{Y}$, Ichinose $\mathrm{T}$, Takano $\mathrm{H}$, et al. Effects of diesel exhaust on allergic airway inflammation in mice. J Allergy Clin Immunol 1998;102:805-12.

6. Whitekus M, Ning Li MJ, Zhang M, et al. Thiol antioxidants inhibit the adjuvant effects of aerosolized diesel exhaust particles in a murine model for ovalbumin sensitization. J Immunol

2002;168:2560-7.

7. Salam MT, Islam T, Gilliland FD. Recent evidence for adverse effects of residential proximity to traffic sources on asthma. Curr Opin Pulm Med 2008;14:3-8.

8. Health Effects Institute. Traffic-related air pollution: a critical review of the literature on emissions, exposure, and health effects. HEI Special Report 2010

9. Jacquemin B, Sunyer J, Forsberg B, et al. Association between modeled traffic-related air pollution and asthma score in the ECRHS. Eur Respir J 2009;34:834-42.
10. McConnell R, Islam T, Shankardass K, et al. Childhood incident asthma and traffic-related air pollution at home and school. Environ Health Perspect 2010;118:1021-6.

11. Gent JF, Koutrakis P, Belanger K, et al. Symptoms and medication use in children with asthma and traffic-related sources of fine particle pollution. Environ Health Perspect 2009;117:1168-74.

12. McCreanor J, Cullinan P, Nieuwenhuijsen MJ, et al. Respiratory effects of exposure to diesel traffic in persons with asthma. $N$ Engl J Med 2007;357:2348-58.

13. Salvi S, Blomberg A, Rudell B, et al. Acute inflammatory responses in the airways and peripheral blood after short-term exposure to diesel exhaust in healthy human volunteers. Am J Respir Crit Care Med 1999; 159:702-9.

14. Nightingale JA, Maggs $R$, Cullinan $P$, et al. Airway inflammation after controlled exposure to diesel exhaust particulates. Am J Respir Crit Care Med 2000;162:161-6.

15. Behndig AF, Mudway IS, Brown JL, et al. Airway antioxidant and inflammatory responses to diesel exhaust exposure in healthy humans. Eur Respir $J$ 2006;27:359-65.

16. Nordenhäll C, Pourazar J, Ledin MC, et al. Diesel exhaust enhances airway responsiveness in asthmatic subjects. Eur Respir J 2001;17:909-15.
17. Stenfors N, Nordenhäll C, Salvi SS, et al. Different airway inflammatory responses in asthmatic and healthy humans exposed to diesel. Eur Respir J 2004;23:82-6.

18. Behndig AF, Larsson N, Brown JL, et al. Pro-inflammatory doses of diesel exhaust in healthy subjects fail to elicit equivalent or augmented airway inflammation in asthmatics. Thorax 2011;66: 12-19.

19. Li N, Hao M, Phalen RF, et al. Particulate air pollutants and asthma. A paradigm for the role of oxidative stress in PM-induced adverse health effects. Clin Immunol 2003;109:250-65.

20. Diaz-Sanchez D, Tsien A, Fleming J, et al. Combined diesel exhaust particulate and ragweed allergen challenge markedly enhances human in vivo nasal ragweed-specific $\operatorname{lgE}$ and skews cytokine production to a T helper cell 2-type pattern. J Immunol 1997;158:2406-13.

21. Diaz-Sanchez D, Garcia MP, Wang M, et al. Nasal challenge with diesel exhaust particles can induce sensitization to a neoallergen in the human mucosa J Allergy Clin Immunol 1999;104:1183-8.

22. Gilliland FD, Li YF, Saxon A, et al. Effect of glutathione-S-transferase M1 and P1 genotypes on xenobiotic enhancement of allergic responses: randomised, placebo-controlled crossover study. Lancet 2004;363:119-25. 